\title{
Assessing fetal growth impairments based on family data as a tool for identifying high-risk babies. An example with neonatal mortality Carsten B Pedersen*1, Yuelian Sun², Mogens Vestergaard ${ }^{2,3}$, Jørn Olsen ${ }^{3,4}$ and Olga Basso ${ }^{5}$
}

\author{
Address: ${ }^{1}$ National Centre for Register-based Research, University of Aarhus, Aarhus, Denmark, ${ }^{2}$ Institute of Public Health, Department of \\ Epidemiology, University of Aarhus, Aarhus, Denmark, ${ }^{3}$ Institute of Public Health, Department of General Practice, University of Aarhus, Aarhus, \\ Denmark, ${ }^{4}$ Department of Epidemiology, School of Public Health, UCLA, Los Angeles, CA, USA and ${ }^{5}$ Epidemiology Branch, National Institutes \\ of Environmental Health Sciences (National Institutes of Health, Department of Health and Human Services), Research Triangle Park, NC, USA \\ Email: Carsten B Pedersen* - cbp@ncrr.dk; Yuelian Sun - YS@SOCI.AU.DK; Mogens Vestergaard - MOGENS.VESTERGAARD@ALM.AU.DK; \\ Jørn Olsen - jo@ucla.edu; Olga Basso - bassoo2@niehs.nih.gov \\ * Corresponding author
}

Published: 28 November 2007

BMC Pregnancy and Childbirth 2007, 7:28 doi:10.1186/1471-2393-7-28

This article is available from: http://www.biomedcentral.com/I47/-2393/7/28

(C) 2007 Pedersen et al; licensee BioMed Central Ltd.

This is an Open Access article distributed under the terms of the Creative Commons Attribution License (http://creativecommons.org/licenses/by/2.0), which permits unrestricted use, distribution, and reproduction in any medium, provided the original work is properly cited.
Received: 5 April 2007

Accepted: 28 November 2007

\begin{abstract}
Background: Low birth weight is associated with an increased risk of neonatal and infant mortality and morbidity, as well as with other adverse conditions later in life. Since the birth weight-specific mortality of a second child depends on the birth weight of an older sibling, a failure to achieve the biologically intended size appears to increase the risk of adverse outcome even in babies who are not classified as small for gestation. In this study, we aimed at quantifying the risk of neonatal death as a function of a baby's failure to fulfil its biologic growth potential across the whole distribution of birth weight.
\end{abstract}

Methods: We predicted the birth weight of 4I I,957 second babies born in Denmark (1979-2002), given the birth weight of the first, and examined how the ratio of achieved birth weight to predicted birth weight performed in predicting neonatal mortality.

Results: For any achieved birth weight category, the risk of neonatal death increased with decreasing birth weight ratio. However, the risk of neonatal death increased with decreasing birth weight, even among babies who achieved their predicted birth weight.

Conclusion: While a low achieved birth weight was a stronger predictor of mortality, a failure to achieve the predicted birth weight was associated with increased mortality at virtually all birth weights. Use of family data may allow identification of children at risk of adverse health outcomes, especially among babies with apparently "normal" growth.

\section{Background}

Birth weight correlates with the risk of perinatal and infant mortality and morbidity [1-4], as well as with a number of health conditions later in life, including cardiovascular diseases, type 2 diabetes, obesity [5-7], and cog- nitive function [8]. However, not all small babies are growth-restricted, as some will just be constitutionally small [9], and not all babies of "normal" size are appropriately grown. For this reason, we need better methods to identify growth restricted babies, especially in epidemio- 
logical studies. There is a strong tendency to repeat birth weight in successive births of the same mother [10-13], and several studies have shown that mortality in second babies varies not only as a function of their own birth weight, but depends also on the birth weight of their older sibling, as small babies whose older sibling was also small had lower mortality than small babies whose older sibling was large $[10,11,14,15]$. These studies, however, did not take gestational age of either child into consideration. Basso et al [16] showed that classifying babies as "growth restricted" based on their expected size predicted delayed motor development at 6 months slightly better than the usual criterion of small-for-gestation, and that combining the two criteria may thus improve prediction. Mortality is recorded essentially without error and could be considered as an extreme on a continuum of unfavourable outcomes. Quantifying the risk associated with the deviation from one's predicted birth weight, regardless of the birth weight itself, will strengthen the case for early identification of at-risk babies, especially in circumstances where there is no obvious fetal growth restriction.

In this study, we aimed at quantifying the risk of neonatal death as a function of a baby's failure to fulfil its predicted growth potential across the whole distribution of birth weight, including the "normal" range. To this end, we predicted the birth weight of 411,957 second babies born alive in Denmark between 1979 and 2002 using a modified version of the method proposed by Skjaerven et al [12].

\section{Methods \\ Data}

The Danish Civil Registration System (CRS) [17], which includes continuously updated information on vital status, was established in 1968, when all residents of Denmark were assigned a unique identifier (CRS number). All Danish national registries are based on this identifier, enabling accurate linkage between them. We linked the individual information recorded in the CRS to that of the Danish Medical Birth Registry [18] which includes the birth record of all live births in Denmark since 1973. Due to secular changes in recording, we restricted our analysis to children born between 1979 and 2002, the most recent year with fully updated information at the time this study was initiated. Because of digit preference primarily to the nearest 100 grams, we rounded birth weight to the nearest 100 grams interval. Gestational age is based on the date of last menstrual period, but often corrected by ultrasound measurements, especially in the most recent period. Gestational age was recorded in completed weeks between 1978 and 1996, and in days from 1997 onward.

During the study period, there were $1,476,753$ live births to Danish residents, all of which are included in the Med- ical Birth Registry. We excluded 51,372 (3.5\%) births due to missing information on birth weight or gestational age.

\section{Inconsistencies in gestational age}

Gestational age is often estimated with error [19-24], with an excess of unlikely large birth weights among infants with a low gestational age. To assess the consistency between birth weight and gestational age among preterm births, we applied a strategy similar to the mixture of two Normal distributions used previously [20,23]. Maximum likelihood estimates of the mixture model parameters were obtained using the Newton-Rapson Method [25]. We stratified the data by sex and gestational age (Table 1). Among very preterm births (22-33 weeks), we observed a bimodal distribution and thus considered the data as inconsistent if the observed birth weight was greater than three times the standard deviation of the major Gaussian component of the distribution. Overall, 629 (2.7\%) of the 23,425 very preterm births were considered inconsistent (see Table 1). We also applied the mixture model to gestational ages beyond 33 weeks. Like Tentoni et al [20], we found that the two model components overlapped almost completely, thus making the correction unnecessary.

\section{Identification of sibships}

Using data on family members recorded in the CRS [17], we identified all sibships in Denmark consisting of firstand second-born singletons born alive between 1979 and 2002 (481,526 sibships). The pair of siblings had the same mother, but not necessarily the same father. We restricted the analyses to sibships with available and credible information on birth weight and gestational age of both babies, and to instances in which both live-born babies had a gestational age of at least 28 completed weeks $(411,957$ sibships). The included sibships constitute $86 \%(=411,957 / 481,526)$ of the total number of sibships where the first and second baby were both born in Denmark during the study period.

\section{Prediction of birth weight in second-born babies}

We first calculated the predicted birth weight of secondborn babies using the strategy described by Skjaerven et al [12], based on the younger sibling's sex and gestational age and on the older sibling's birth weight. Since this approach did not take into consideration either the firstborn's sex or gestational age, we explored whether including these factors improved the prediction. Since the variance of birth weight increases with increasing gestational age, the model used to predict the birth weight of the second-born needs to allow for this heterogeneity. Therefore, we used a variance component model [26] to predict the second-born's birth weight, using the first birth weight as a linear term for each stratum of gestational age of firstand second-born babies, with a common sex correction. The birth weights of the second-born babies were 
Table I: Parameters of the major and secondary components in the mixture of two Normal distributions of birth weight among preterm births (22-33 weeks) stratified by gestational age and sex

\begin{tabular}{|c|c|c|c|c|c|c|c|c|c|}
\hline Gestational age (weeks) & $22-23$ & $24-25$ & $26-27$ & 28 & 29 & 30 & 31 & 32 & 33 \\
\hline \multicolumn{10}{|l|}{ Girls } \\
\hline Sample size & 49 & 93 & 507 & 2017 & 917 & 1464 & $|72|$ & 2659 & 3503 \\
\hline$\mu_{\mathrm{m}}:$ Mean major Gaussian $(\mathrm{g})$ & 556 & 713 & 913 & 1071 & 1216 & 1344 & $154 \mid$ & 1730 & 1934 \\
\hline$\sigma_{\mathrm{m}}:$ Std major Gaussian $(\mathrm{g})$ & 125 & 134 & 182 & 213 & 258 & 277 & 306 & 317 & 363 \\
\hline$\mu_{s}:$ Mean sec. Gaussian $(\mathrm{g})$ & 2771 & 3800 & $2|4|$ & 2848 & 2182 & 3103 & 2556 & 2207 & 2322 \\
\hline$\sigma_{\mathrm{s}}:$ Std sec. Gaussian (g) & 591 & 150 & 805 & 657 & 532 & 613 & 1244 & 787 & 755 \\
\hline$P_{s}:$ Weight sec. Gaussian (\%) & 3.6 & 0.5 & 3.3 & 2.7 & 1.9 & 8.2 & 4.5 & 7.8 & 9.8 \\
\hline Threshold (g) \& & 931 & 1115 & 1459 & 1710 & 1990 & 2175 & 2459 & 2681 & 3023 \\
\hline Number of births above threshold & 5 & 5 & 25 & 20 & 17 & 92 & 35 & 52 & 51 \\
\hline \multicolumn{10}{|l|}{ Boys } \\
\hline Sample size & 49 & 85 & 422 & 1629 & 808 & 1176 & 1357 & 2111 & 2956 \\
\hline$\mu_{\mathrm{m}}:$ Mean major Gaussian $(\mathrm{g})$ & 601 & 769 & 969 & 1148 & 1299 & 1434 & 1629 & 1828 & 2040 \\
\hline$\sigma_{\mathrm{m}}:$ Std major Gaussian $(\mathrm{g})$ & 119 & 150 & 191 & 224 & 243 & 298 & 322 & 335 & 378 \\
\hline$\mu_{s}:$ Mean sec. Gaussian $(g)$ & 2850 & 3479 & 2706 & 2662 & 2209 & 3301 & 2808 & 2248 & 3331 \\
\hline$\sigma_{s}:$ Std sec. Gaussian $(\mathrm{g})$ & 354 & 991 & 947 & 978 & 1105 & 907 & 1433 & 842 & 551 \\
\hline $\mathrm{P}_{\mathrm{s}}:$ Weight sec. Gaussian (\%) & 4.3 & 2.7 & 2.3 & 3.3 & 4.9 & 7.8 & 3.2 & 7.2 & 1.4 \\
\hline Threshold $(g)$ \& & 958 & 1219 & 1542 & 1820 & 2028 & 2328 & 2595 & 2833 & 3174 \\
\hline Number of births above threshold & 4 & 16 & 28 & 28 & 27 & 103 & 34 & 54 & 33 \\
\hline
\end{tabular}

\& The threshold was estimated as the mean $\mu_{\mathrm{m}}$ of the major Gaussian distribution plus 3 times the standard deviation $\sigma_{\mathrm{m}}$ of the major Gaussian distribution. Birth weights above this threshold were considered as inconsistent with gestational age and excluded from the analysis.

assumed to be independent and normally distributed with a variance depending on their gestational age only. The model used to predict the absolute birth weight of the second-born baby was analogous to using a separate linear normal regressions for each stratum of gestational age of first- and second-born babies, except that we used a common sex correction independent of the gestational age of either baby and we constrained the variance of the second-born babies birth weights to be the same across all first-born's gestational ages.

We thus used the following equation to predict the birth weight of the second-born baby:

$$
\operatorname{Pred}\left(\mathrm{W}_{2}\right)=\mathrm{I}\left(\mathrm{g}_{1}, \mathbf{g}_{2}\right)+\beta\left(\mathrm{g}_{1}, \mathrm{~g}_{2}\right){ }^{*} \mathbf{w}_{1}+\gamma\left(\mathrm{s}_{1}, \mathbf{s}_{2}\right),
$$

where

$\operatorname{Pred}\left(\mathrm{W}_{2}\right)$ : predicted birth weight of the second-born child,

$\mathrm{I}\left(\mathrm{g}_{1}, \mathrm{~g}_{2}\right)$ : estimated intercept among sibs where the firstborn had a gestational age of $\mathbf{g}_{1}$ and the second-born had a gestational age of $\mathbf{g}_{2}$.

$\beta\left(g_{1}, g_{2}\right)$ : estimated slope among sibs where the first-born had a gestational age of $g_{1}$ and the second-born had a gestational age of $\mathbf{g}_{2}$ $\mathbf{w}_{1}$ : first-born baby's observed birth weight

$\gamma\left(\mathbf{s}_{1}, \mathbf{s}_{2}\right)$ : estimated sex correction depending of the firstborns sex $\left(s_{1}\right)$ and the second-borns sex $\left(s_{2}\right)$

Note: All parameters were estimates simultaneously using a variance component model.

In these analyses, first-borns' gestational age $\left(\mathrm{g}_{1}\right)$ was categorized as $28-33,34-35,36-37,38-39,40-41$, and >= 42 completed weeks, and second-borns' gestational age $\left(\mathrm{g}_{2}\right)$ was categorized as $28-29,30-31,32-33,34,35,36$, $37,38,39,40,41$, and $>=42$ weeks. Since we expected gestational age of the second-born babies to be more important for predicting their own birth weight than gestational age of their older sibling, we decided a priori to use a more detailed categorization of gestational age for the second-born. For each gestational age of the first- and second-born, the parameters of intercept $\mathrm{I}\left(\mathrm{g}_{1}, \mathrm{~g}_{2}\right)$ and slope $\beta\left(g_{1}, g_{2}\right)$ are presented in Table 2. At the foot of the Table, the estimated common sex correction $\gamma\left(\mathbf{s}_{1}, \mathbf{s}_{2}\right)$ is shown for each of the four combinations (female female, female - male, male - female, male - male).

Initially, we investigated the assumption that the variance of the second-born babies birth weights were the same across all first-born's gestational ages. Though, significant variation was observed, the estimated variance seemed to 
Table 2: Parameters of intercept $(\mathrm{I})$ and slope $(\beta)$ for predicting the birth weights of second-born children based on gestational age and sex * of first- and second-born children.

\begin{tabular}{|c|c|c|c|c|c|c|c|c|c|c|c|c|c|c|c|c|c|c|c|}
\hline \multirow{3}{*}{$\begin{array}{l}\text { Gestational age } \\
\text { of second child } \\
\text { (gl: weeks) }\end{array}$} & \multicolumn{18}{|c|}{ Gestational age of first child ( $g_{2}:$ weeks) } & \multirow{3}{*}{ SD } \\
\hline & \multicolumn{3}{|c|}{$28-33$} & \multicolumn{3}{|c|}{$34-35$} & \multicolumn{3}{|c|}{$36-37$} & \multicolumn{3}{|c|}{$38-39$} & \multicolumn{3}{|c|}{ 40-41 } & \multicolumn{3}{|c|}{$>=42$} & \\
\hline & No. & 1 & $\beta$ & No. & 1 & $\beta$ & No. & I & $\beta$ & No. & $\mathrm{I}$ & $\beta$ & No. & 1 & $\beta$ & No. & I & $\beta$ & \\
\hline $28-29$ & 62 & 900 & 0.198 & 46 & 615 & 0.283 & 55 & 850 & 0.150 & 164 & 1030 & 0.066 & 190 & 735 & 0.148 & 37 & 840 & 0.111 & 240 \\
\hline $30-31$ & 117 & 980 & 0.348 & 65 & 740 & 0.385 & 114 & 1110 & 0.177 & 256 & 1050 & 0.168 & 309 & 880 & 0.207 & 42 & 195 & 0.359 & 320 \\
\hline $32-33$ & 167 & 1430 & 0.360 & 149 & 1270 & 0.312 & 293 & 920 & 0.407 & 557 & 1470 & 0.171 & 613 & 1230 & 0.224 & 78 & 1220 & 0.231 & 360 \\
\hline 34 & 144 & 1650 & 0.407 & 196 & 1395 & 0.450 & 281 & 1075 & 0.462 & 563 & 1150 & 0.382 & 591 & 1140 & 0.352 & 83 & 1265 & 0.304 & 440 \\
\hline 35 & 200 & 1675 & 0.496 & 261 & 1285 & 0.575 & 529 & 865 & 0.632 & 925 & 1095 & $0.48 I$ & 941 & 1230 & 0.397 & 124 & 1255 & 0.379 & 440 \\
\hline 36 & 301 & 2005 & 0.439 & 426 & 1140 & 0.722 & 1107 & 1110 & 0.649 & 2026 & 1335 & 0.490 & 1975 & 1365 & 0.439 & 244 & 1500 & 0.378 & 435 \\
\hline 37 & 495 & 2450 & 0.341 & 712 & 1705 & 0.566 & 2420 & 1465 & 0.588 & 5388 & 1380 & 0.553 & 5147 & 1270 & 0.539 & 619 & 1385 & 0.485 & 435 \\
\hline 38 & 659 & 2660 & 0.296 & 1132 & 2095 & 0.488 & 4263 & 1735 & 0.546 & 16229 & 1650 & 0.526 & 17312 & 1560 & 0.521 & 2329 & 1685 & 0.468 & 400 \\
\hline 39 & 806 & 3050 & 0.212 & 1385 & 2355 & 0.448 & 5872 & 2030 & 0.501 & 31014 & 1750 & 0.541 & 43119 & 1690 & 0.534 & 5487 & 1790 & 0.490 & 385 \\
\hline $40-41$ & 1204 & 3295 & 0.171 & 1863 & 2785 & 0.344 & 8110 & 2345 & 0.446 & 51057 & 1855 & 0.553 & 132010 & 1780 & 0.554 & 25393 & 1905 & 0.510 & 390 \\
\hline$>=42$ & 145 & 3520 & 0.125 & 182 & 3385 & 0.184 & 695 & 2670 & 0.382 & 4692 & 2220 & 0.488 & 19508 & 1855 & 0.568 & 8479 & 1960 & 0.531 & 415 \\
\hline
\end{tabular}

No: Number of sibships included.

SD: Estimated Standard Deviation based on the regression model.

* The estimated sex correction $\left(\gamma\left(\mathbf{s}_{1}, \mathbf{s}_{2}\right)\right)$ is:

-- I.st female - 2.nd female: -65 grams

-- I.st female -2 .nd male: +85 grams,

-- I.st male - 2.nd female: -145 grams,

-- I.st male - 2.nd male: 0 grams (reference).

Example

According to the model used, for a baby boy at 39 weeks of gestation with an older brother who weighed 2000 grams at 34-35 week of gestation, had a predicted birth weight of $325 \mathrm{I}$ grams (Table $2, \mathbf{I}\left(\mathbf{g}_{1}=\mathbf{3 4}-\mathbf{3 5}, \mathbf{g}_{\mathbf{2}}=\mathbf{3 9}\right)=2355, \beta\left(\mathbf{g}_{1}=\mathbf{3 4}-\mathbf{3 5}, \mathbf{g}_{\mathbf{2}}=\mathbf{3 9}\right)=0.448, \gamma\left(\mathbf{s}_{1}=\mathbf{m a l e}, \mathbf{s}_{\mathbf{2}}=\mathbf{m a l e}\right)=0$, i.e., predicted birth weight $=2355+0.448 * 2000$ grams +0$)$. Similarly, if the second-born was a girl, she would have a predicted birth weight of 3106 grams (Table 2, I $\left(\mathbf{g}_{1}=\mathbf{3 4 - 3 5}, \mathbf{g}_{2}=\mathbf{3 9}\right)=2355, \beta\left(\mathbf{g}_{1}=\mathbf{3 4 - 3 5}, \mathbf{g}_{\mathbf{2}}=\mathbf{3 9}\right)=0.448, \gamma\left(\mathbf{s}_{1}=\mathbf{m a l e}, \mathbf{s}_{2}=\mathbf{f e m a l e}\right)=-\mid 45$ grams, i.e., predicted birth weight $=2355+0.448 * 2000$ grams -145 grams $)$.

vary at no meaningful pattern, and we thus decided not to included this term in the model.

\section{Estimating the relative risk of neonatal death}

Second-born babies were followed from birth to the $27^{\text {th }}$ day of life, death, or emigration from Denmark, whichever came first. Neonatal death was defined as death occurring within 27 days after birth. We estimated the relative risk of neonatal death as a function of the deviation from the predicted birth weight, expressed by the birth weight ratio [(observed birth weight)/(predicted birth weight $) \times 100$ ]. The relative risk of death was estimated by log-linear Poisson regression treating the number of person-years as an offset variable $[27,28]$. All estimated relative risks were adjusted for year of birth, sex, and gestational age of the second baby. Though, we acknowledge that the reported relative risks are in principle incidence rate ratios, we prefer to refer to these as relative risks as most readers are familiar with this term.

\section{Results}

Prediction of birth weight using family data

Figure 1 shows the mean second-born's birth weight according their gestational age and birth weight of their older sibling. At the $39^{\text {th }}$ week of gestation, babies whose older sibling weighed 2000 grams had a mean birth weight of 3175 grams, while babies whose older sibling weighed 5000 grams had a mean birth weight of 4200 grams. These patterns were strikingly similar to those reported by Skjaerven et al [12], who found that, at any given gestational age of the second-born child, there was a linear association between its birth weight and that of the first-born. Additionally, they argued that this association was restricted to sibships in which the first-born weighed at least 2500 grams. Thus, they used a constant term to model the second-born's birth weight when the older sibling weighed less than 2500 grams.

However, when we stratified the results shown in Figure 1 by the first-born's gestational age (Figure 2), we observed a linear association between the second-born's birth weight and the first-born's birth weight for all birth weights of the first-born, including birth weights below 2500 grams. Therefore, we modelled the second-born's birth weight, using the first-born's birth weight as a linear term for each stratum of gestational age of first- and second-born babies. Table 2 shows the estimated parameters obtained through this method, which we used to predict the birth weight of the second-born child.

To compare our prediction with that proposed by Skjaerven et al [12], we applied their equation to the Danish data (results not shown). The overall R-square estimated using our model was 0.48 , very close to that based on the 


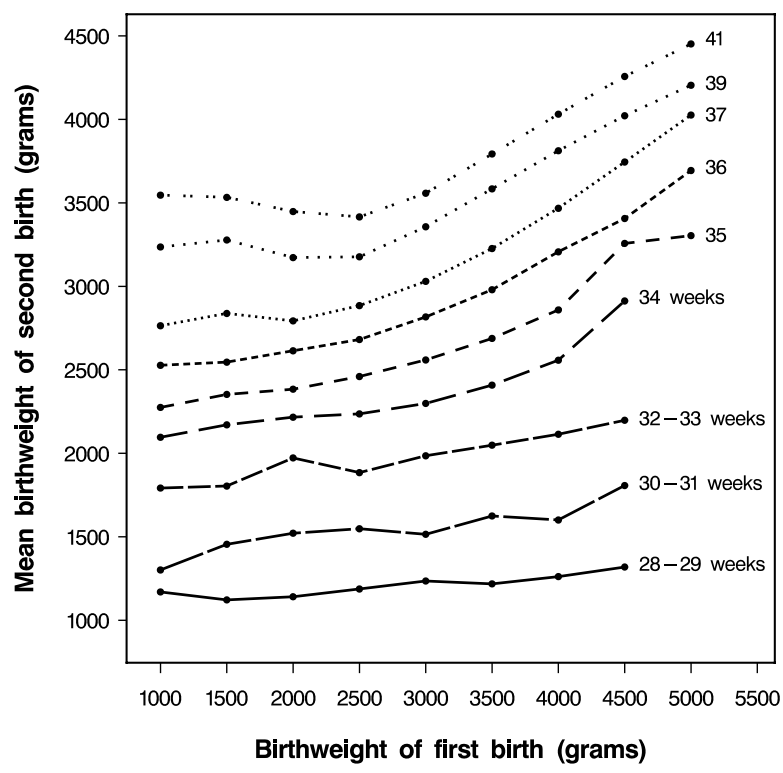

Figure I

Gestational-age specific mean birth weight of second-born children according to the birth weight of their older siblings (Only mean values based on more than 10 babies are shown.)

Norwegian model [12] which was 0.46 . However, the Rsquare by the first-borns' gestational age showed that, the lower the gestational age of the first-born, the better the fit of our model compared to the Norwegian model.

\section{Estimation of the risk of neonatal mortality using family data}

Among the 411,957 second-born children included in the study, 946 died within 27 days after birth, and 30 were lost to follow-up due to emigration from Denmark and were thus censored at the time of emigration.

Within each category of the achieved birth weight, the risk of neonatal death depended on the birth weight ratio (Table 3). In addition, within each category of birth weight ratio, the lower the achieved birth weight, the greater the absolute risk of neonatal death. This was also observed among babies who achieved their predicted birth weight defined as within $90-110 \%$ of the predicted birth weight.

Figure 3 shows the adjusted relative risks of neonatal death (in log scale) for second-born children according to the birth weight ratio and the achieved birth weight. Babies weighing 3500-3999 grams who had achieved their predicted birth weight were chosen as the reference category. The achieved birth weight was strongly predictive of neonatal death, although adjustment for gesta-

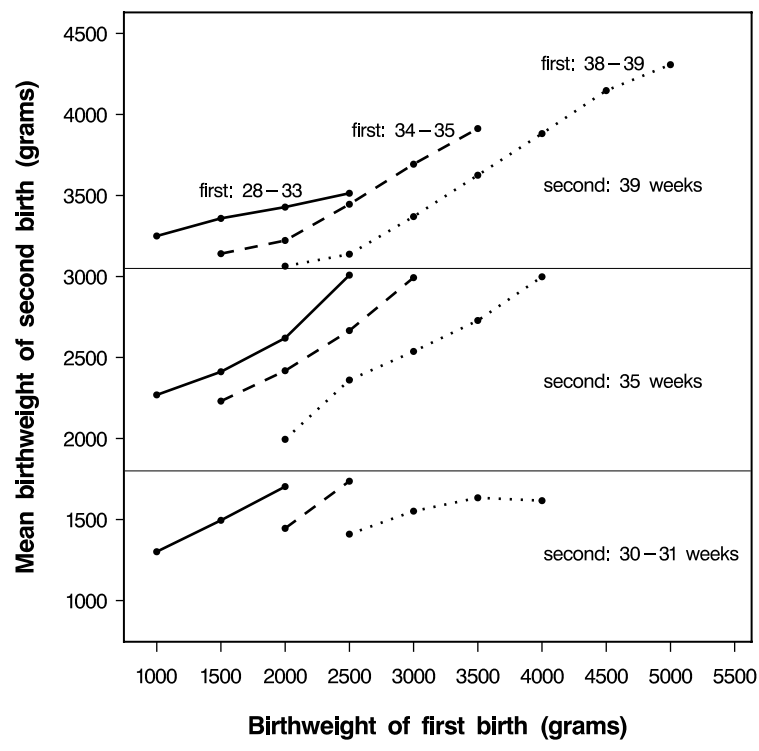

Figure 2

Mean birth weight of second-born children at selected gestational ages [39 (top), 35 (middle), or 30-3। (bottom) weeks] according to the birth weight of first-born children at selected gestational ages [28-33 (solid lines __), 34-35 (punctuated lines ---), and 38-39 (dashed lines ...) weeks]. (Only mean values based on more than 10 babies are shown.)

tional age attenuated the estimates. Among babies who achieved their predicted birth weight and using 35003999 grams as the reference category, the estimated relative risks were 20.6 (95\% CI: 11.0-38.6) for babies weighing < 1500 grams, 13.9 (95\% CI:7.7-24.9) for those weighing 1500-1999 grams, 7.0 (95\% CI: 4.1-12.0) for those with a birth weight between 2000 and 2499 grams, 2.8 (95\% CI: 1.8-4.3) for those weighing 2500-2999 grams, and 1.5 (95\% CI: 1.1-2.0) for those who weighed 3000-3499 grams. Among babies who weighed 35003999 grams, however, those who achieved $80-90 \%$ of the predicted birth weight had a relative risk of 2.0 (95\% CI: 0.9-4.3) compared with those who achieved the predicted birth weight within $\pm 10 \%$. Those who exceeded their predicted birth weight also had slightly elevated, although not statistically significant, relative risks [1.4 (95\% CI: 0.8-2.4) among babies who achieved 110$120 \%$ of the predicted birth weight and 2.3 (95\% CI: $0.9-$ 5.8 ), among those who achieved more than $120 \%$ of their predicted birth weight].

Restricting the analysis to second-born babies born at term (37-41 weeks) whose older siblings were alive at their first birthday yielded similar results (Table 4), but the sample size was considerably reduced. 
Table 3: Number of neonatal deaths, number of babies, and absolute risk according to achieved birth weight and birth weight ratio \& among 4I 1957 (including 946 neonatal deaths) second-born babies (Denmark, 1979-2002)

\begin{tabular}{|c|c|c|c|c|c|c|c|c|c|}
\hline \multicolumn{2}{|c|}{ Birth Weight Ratio \& } & \multicolumn{7}{|c|}{ Achieved birth weight } & \multirow[b]{2}{*}{ Total } \\
\hline & & $<1500 \mathrm{~g}$ & $1500-1999 \mathrm{~g}$ & $2000-2499 \mathrm{~g}$ & $2500-2999 \mathrm{~g}$ & $3000-3499 \mathrm{~g}$ & $3500-3999 \mathrm{~g}$ & $>=4000 \mathrm{~g}$ & \\
\hline \multirow[t]{3}{*}{$<50 \%$} & Deaths & 60 & 14 & 0 & 0 & 0 & 0 & 0 & 74 \\
\hline & Babies & 137 & 35 & 0 & 0 & 0 & 0 & 0 & 172 \\
\hline & Absolute risk $\dagger$ & 437.96 & 400.00 & - & - & - & - & - & 430.23 \\
\hline \multirow[t]{3}{*}{$50-60 \%$} & Deaths & 22 & 20 & 8 & 0 & 0 & 0 & 0 & 50 \\
\hline & Babies & 120 & 184 & 89 & 1 & 0 & 0 & 0 & 394 \\
\hline & Absolute risk $\dagger$ & 183.33 & 108.70 & 89.89 & - & - & - & - & 126.90 \\
\hline \multirow[t]{3}{*}{$60-70 \%$} & Deaths & 15 & 9 & 24 & 6 & 0 & 0 & 0 & 54 \\
\hline & Babies & 133 & 327 & 923 & 287 & 7 & 0 & 0 & 1677 \\
\hline & Absolute risk $\dagger$ & 122.78 & 27.52 & 26.00 & 20.91 & - & - & - & 32.20 \\
\hline \multirow[t]{3}{*}{$70-80 \%$} & Deaths & 23 & 14 & 34 & 36 & 5 & 0 & 0 & 112 \\
\hline & Babies & 205 & 374 & 2182 & 6585 & 1473 & 24 & 0 & 10843 \\
\hline & Absolute risk $\dagger$ & 112.20 & 37.43 & 15.58 & 5.47 & 3.39 & - & - & 10.33 \\
\hline \multirow[t]{3}{*}{$80-90 \%$} & Deaths & 27 & 20 & 16 & 47 & 59 & 7 & 0 & 176 \\
\hline & Babies & 203 & 460 & 1995 & 18662 & 32431 & 4355 & 58 & 58164 \\
\hline & Absolute risk $\dagger$ & 133.01 & 43.48 & 8.02 & 2.52 & 1.82 & 1.61 & - & 3.03 \\
\hline \multirow[t]{3}{*}{$90-110 \% *$} & Deaths & 35 & 31 & 30 & 40 & 100 & 91 & 32 & 359 \\
\hline & Babies & 368 & 779 & 2009 & $|233|$ & 88402 & 125576 & 39621 & 269086 \\
\hline & Absolute risk $\dagger$ & 95.11 & 39.80 & 14.93 & 3.24 & 1.13 & 0.72 & 0.81 & 1.33 \\
\hline \multirow[t]{3}{*}{$110-120 \%$} & Deaths & 17 & 8 & 7 & 7 & 5 & 17 & 19 & 80 \\
\hline & Babies & 90 & 139 & 351 & 706 & 3208 & 16228 & 34574 & 55296 \\
\hline & Absolute risk $\dagger$ & 188.89 & 57.55 & 19.94 & 9.92 & 1.56 & 1.05 & 0.55 & 1.45 \\
\hline \multirow[t]{3}{*}{$>=120 \%$} & Deaths & 5 & 6 & 6 & 6 & 4 & 5 & 9 & 41 \\
\hline & Babies & 30 & 121 & 191 & 346 & 702 & 2268 & 12667 & 16325 \\
\hline & Absolute risk $\dagger$ & 166.67 & 49.59 & 31.41 & 17.34 & 5.70 & 2.20 & 0.71 & 2.51 \\
\hline \multirow[t]{3}{*}{ Total } & Deaths & 204 & 122 & 125 & 142 & 173 & 120 & 60 & 946 \\
\hline & Babies & 1286 & 2419 & 7740 & 38918 & 126223 & $|4845|$ & 86920 & 411957 \\
\hline & Absolute risk $\dagger$ & 158.63 & 50.43 & 16.15 & 3.65 & 1.37 & 0.81 & 0.69 & 2.30 \\
\hline
\end{tabular}

\& Achieved birth weight divided by predicted birth weight times 100

$\dagger$ Crude absolute risk of neonatal death per 1000 babies.

$*$ Babies who achieved their predicted birth weight within $+/-10 \%$

- indicates that the data were too sparse to provide a reliable estimate

In general, for any achieved birth weight above 2000 grams, there was an inverse J-shaped association between the birth weight ratio and the relative risk of neonatal death. Babies with the lowest birth weight ratio had the highest relative risk. Except for the category 2500-2999 grams, babies who achieved their predicted birth weight had the lowest risk. Adding the birth weight ratio to the model already including birth weight and gestational age significantly improved the fit (chi-square $=252.41, \mathrm{df}=$ $32, \mathrm{p}<0.0001)$.

\section{Discussion}

In this study, failure to fulfil the estimated growth potential increased the risk of neonatal death. Several authors $[10,11,14,15]$ indicated that weight-specific mortality of the second child depends in part on the birth weight of the first child. After additionally taking into consideration gestational age of both infants, our observations further suggest that deviations from the predicted birth weight contribute to mortality across the whole distribution of birth weights. At virtually all birth weights, babies whose achieved birth weight was below $90 \%$ of the predicted had an increased risk of neonatal death. Thus, prediction of neonatal death in second-born babies is significantly improved by adding the deviation from the predicted birth weight; even though a low achieved birth weight remained the stronger predictor.

The heterogeneity in risk of neonatal death observed among babies within the same weight category provides further evidence that birth weight alone is an incomplete marker of fetal growth although, used alone, the birth weight ratio would be an even poorer predictor at the lower birth weights. However, in the absence of clinical information, the birth weight ratio may be particularly useful in the "normal" range of birth weight. 


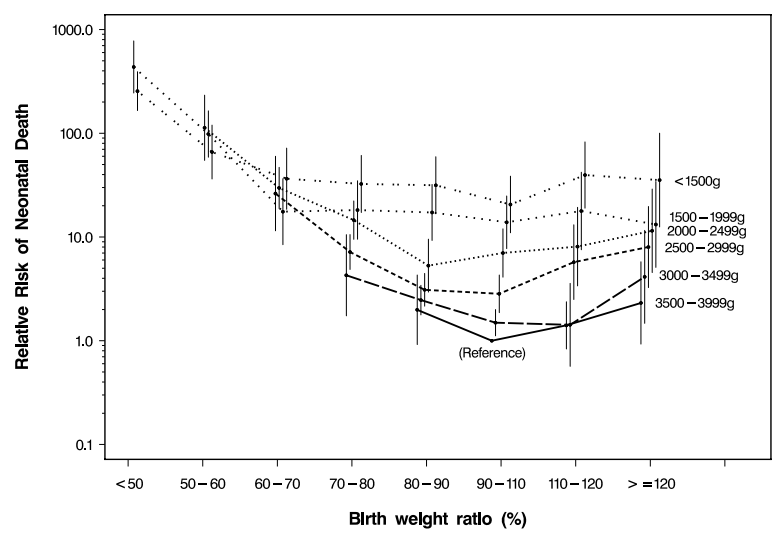

Figure 3

Adjusted relative risk of neonatal death (log scale) of secondborn children according to the birth weight ratio by stratifying the achieved birth weight (Babies with an achieved birth weight of $3500-3999 \mathrm{~g}$ and a birth weight ratio of $90-109 \%$ were chosen as the reference). Estimates were based on 4I 957 babies, including 946 neonatal deaths (Denmark 1977-2000). Vertical bars indicate $95 \%$ confidence intervals.

Methodological considerations in predicting birth weight Unlike Skjaerven et al [12], we chose not to adjust for trends in birth weight by calendar time, since an increase in birth weight with birth year ( 6 grams per year) was in part accounted for by the older sibling's birth weight, and since the interval between pregnancies was relatively short (mean: 3.5 yrs, $\mathrm{SD} \pm 2.0$ yrs). Additionally, we took into consideration sex and gestational age of both the first and second babies, rather than only those of the second, as proposed by Skjaerven et al [12]. However, to reduce the complexity of the prediction equation, our correction for sex was the same across all gestational ages of both infants.

The main limitation of this approach is that it requires an older sibling to make the prediction. In the absence of a sibling, other models have been proposed to predict birth weight, such as measures based on maternal characteristics [29,30] or using the mother's own birth weight [12]. Our proposed approach requires gestational age of both children and, since gestational age is prone to misclassification, this may be a source of additional error. Even so, including gestational age of both children slightly improved the fit of the predicted birth weight, especially if the first-born child had a low birth weight.

When the birth weight of the first baby is extremely small or extremely high, due to either measurement error or natural variability, this will lead to attenuation of the relation between the birth weights of the two siblings. While this may reduce the ability of the model to predict birth weight, gestational age and birth weight of the older child still explained a large fraction (48\%) of the total variation of the birth weight of the younger child.

\section{Birth weight ratio and mortality}

When we examined the risk of neonatal death of the second baby as a function of how close the achieved birth weight was to the predicted birth weight (birth weight ratio), we observed an inverse J-shaped curve for all strata of achieved birth weight above 2000 grams; overall, mortality was higher for infants with a low birth weight ratio, lower for infants who achieved their predicted birth weight, and slightly higher for infants who achieved a birth weight higher than predicted. However, a low achieved birth weight was more strongly associated with a high risk of mortality, even among babies who fulfilled their prediction, and after adjustment for gestational age, which illustrates the limitations in making predictions in the absence of clinical data. Our results indicate that babies within the same category of birth weight have different risks of mortality, as previously suggested [31], depending in part on how well the achieved birth weight agrees with the predicted birth weight. Although the power was considerable reduced, the results were virtually unchanged after restricting the analysis to second-born children born at term whose older sibling survived at least to their $1^{\text {st }}$ birthday.

Our findings showed that a previous child allows a more individualized prediction of birth weight than gestational age alone. The second baby may differ genetically from the older sibling, but it has been suggested that maternal characteristics correlate with birth weight more closely than fetal genes [32]. Whether the first-born child is a valid representative of the growth potential for later children of the same mother may be questionable. If the first baby was growth-restricted, then the birth weight predicted for the second baby will be off the mark to an extent depending on the first-born's degree of growth restriction. Basso et al [33] showed that a rare confounder that strongly decreases birth weight and increases mortality could, at least in theory, explain the whole association between low birth weight and mortality. If a factor with these characteristics exists, and if it has a tendency to recur within the same mother, this would contribute to explaining why even term babies who fulfil their predicted birth weight have a high mortality if their achieved birth weight is low. This could also occur with less severe - and well known-determinants of growth restriction, such as smoking, if they are present in both pregnancies. Babies of mothers with these characteristics will have a "wrong" predicted birth weight and be at higher risk of death even when babies fulfil their prediction. This will be a problem with any time-stable exposure or condition that decreases 
Table 4: Number of neonatal deaths, number of babies, and absolute risk according to achieved birth weight and birth weight ratio\& among 360523 second-born term babies (37-4I weeks) whose older sibling were alive at the first birthday (504 neonatal deaths) (Denmark, 1979-2002).

\begin{tabular}{|c|c|c|c|c|c|c|c|c|c|}
\hline \multicolumn{2}{|c|}{ Birth Weight Ratio \& } & \multicolumn{7}{|c|}{ Achieved birth weight } & \multirow[b]{2}{*}{ Total } \\
\hline & & $<1500 \mathrm{~g}$ & $1500-1999 \mathrm{~g}$ & $2000-2499 \mathrm{~g}$ & $2500-2999 \mathrm{~g}$ & $3000-3499 \mathrm{~g}$ & $3500-3999 \mathrm{~g}$ & $>=4000 \mathrm{~g}$ & \\
\hline \multirow[t]{3}{*}{$<50 \%$} & Deaths & 37 & 14 & 0 & 0 & 0 & 0 & 0 & 51 \\
\hline & Babies & 67 & 33 & 0 & 0 & 0 & 0 & 0 & 100 \\
\hline & Absolute risk $\dagger$ & 552.24 & 424.24 & - & - & - & - & - & 510.00 \\
\hline \multirow[t]{3}{*}{$50-60 \%$} & Deaths & I & 13 & 8 & 0 & 0 & 0 & 0 & 22 \\
\hline & Babies & 9 & 147 & 85 & 1 & 0 & 0 & 0 & 242 \\
\hline & Absolute risk $\dagger$ & - & 88.44 & 94.12 & - & - & - & - & 90.91 \\
\hline \multirow[t]{3}{*}{$60-70 \%$} & Deaths & 0 & I & 21 & 5 & 0 & 0 & 0 & 27 \\
\hline & Babies & 0 & 140 & 856 & 233 & 6 & 0 & 0 & 1235 \\
\hline & Absolute risk $\dagger$ & - & - & 24.53 & 21.46 & - & - & - & 21.86 \\
\hline \multirow[t]{3}{*}{$70-80 \%$} & Deaths & 0 & 0 & 20 & 30 & 3 & 0 & 0 & 53 \\
\hline & Babies & 0 & 44 & 1829 & 6047 & 1153 & 16 & 0 & 9098 \\
\hline & Absolute risk $\dagger$ & - & - & 10.93 & 4.96 & 2.60 & - & - & 5.83 \\
\hline \multirow[t]{3}{*}{$80-90 \%$} & Deaths & 0 & 0 & 3 & 43 & 54 & 6 & 0 & 106 \\
\hline & Babies & 0 & 6 & 935 & 17559 & 28852 & 3231 & 39 & 50622 \\
\hline & Absolute risk $\dagger$ & - & - & 3.20 & 2.45 & 1.87 & 1.86 & - & 2.09 \\
\hline \multirow{3}{*}{$90-110 \% *$} & Deaths & 0 & 0 & I & 12 & 88 & 76 & 27 & 204 \\
\hline & Babies & 0 & 1 & 162 & 9092 & 83708 & 113119 & 31627 & 237709 \\
\hline & Absolute risk $\dagger$ & - & - & - & 1.31 & 1.05 & 0.67 & 0.85 & 0.86 \\
\hline \multirow[t]{3}{*}{$110-120 \%$} & Deaths & 0 & 0 & 0 & 0 & I & 16 & 14 & 31 \\
\hline & Babies & 0 & 0 & 2 & 116 & 2408 & 15527 & 30146 & 48199 \\
\hline & Absolute risk $\dagger$ & - & - & - & - & - & 1.03 & 0.46 & 0.64 \\
\hline \multirow[t]{3}{*}{$>=120 \%$} & Deaths & 0 & 0 & 0 & 0 & 1 & 1 & 8 & 10 \\
\hline & Babies & 0 & 0 & 2 & 20 & 279 & 1842 & 11184 & 13327 \\
\hline & Absolute risk $\dagger$ & - & - & - & - & - & - & $0.7 \mathrm{I}$ & 0.75 \\
\hline \multirow[t]{3}{*}{ Total } & Deaths & 38 & 28 & 53 & 90 & 147 & 99 & 49 & 504 \\
\hline & Babies & 76 & 371 & 3871 & 33068 & 116406 & 133735 & 72996 & 360523 \\
\hline & Absolute risk $\dagger$ & 500.00 & 75.47 & 13.69 & 2.72 & 1.26 & 0.74 & 0.67 & 1.39 \\
\hline
\end{tabular}

\& Achieved birth weight divided by predicted birth weight times 100

+Crude absolute risk of neonatal death per 1000 babies.

* Babies who achieved their predicted birth weight within +/- 10\%.

- indicates that the data were too sparse to provide a reliable estimate

- or increases - birth weight and increases the risk of neonatal death or of other health problems.

Our study spans a long time period, during which important improvements in the care of premature newborns have occurred. The relatively small absolute number of deaths in our study did not permit analyses of separate time periods. However, adjusting for year of birth did not change our estimates. Our results only refer to neonatal mortality in singleton live births. Results for post-neonatal mortality may be different. Our study is further limited by the lack of information on congenital anomalies or infections, as these conditions increase the risk of both growth restriction and neonatal death. This will limit the predictive value of our estimates, especially at the lower weights. As these conditions may be present in both pregnancies, this mechanism may, in part, explain the strong predictive risk of a small achieved birth weight among babies who appeared to have fulfilled their growth potential. Similarly, we did not have information on maternal morbidity in either pregnancy, and the mother's health status is likely to play an important role in growth.

The main utility of the proposed approach lies, however, in its ability to provide a framework for assessing risk among babies with apparently "normal" birth weight. If individuals whose fetal growth was compromised have an increased risk for adverse health conditions, early identification may improve their outcome through monitoring or intervention. In the presence of detailed clinical information, the proposed method is unlikely to help physicians assess individual risk. However, a discrepancy in birth weight between siblings may constitute a warning sign even in the absence of obvious pathology, and such babies may benefit from increased surveillance. Babies who failed to achieve their predicted birth weight but were 
classified as "normal" by the regular criterion of small-forgestation appeared to be at higher risk of delayed motor development [16]. It is thus of interest to explore whether this applies to other outcomes as well, especially among researchers interested in assessing the medium- and longterm effects of impaired fetal growth.

\section{Conclusion}

Our results lend further credibility to the notion that impaired fetal growth is a marker of compromised development. While a low achieved birth weight was a stronger predictor of mortality, a failure to achieve the predicted birth weight was associated with increased mortality at virtually all birth weights. The approach described here may aid clinicians in the identification of babies at higher risk among those with a birth weight in the normal range. It should also be considered as a tool in epidemiologic studies that aim at studying medium- and long-term consequences of fetal growth disruptions.

\section{Competing interests}

The author(s) declare that they have no competing interests.

\section{Authors' contributions}

All authors contributed to the idea and conception of the study. CBP and OB suggested the initial design of the study. All authors contributed to the final design used. CBP analysed the data. All authors contributed to the interpretation of data. $\mathrm{CBP}$ and $\mathrm{OB}$ drafted the manuscript. All authors revised the manuscript critically for important intellectual content. All authors read and approved the final manuscript.

\section{Acknowledgements}

The study was supported by the Danish Research Agency (grant no: 22-020207), P.A. Messerschmidt and Wife's Foundation, Managing Director Kurt Bønnelycke and Mrs Grethe Bønnelyckes Foundation, Aase and Ejnar Danielsen's Foundation, and the Intramural Program of the NIH, National Institutes of Environmental Health Sciences.

\section{References}

I. Tan TY, Yeo GS: Intrauterine growth restriction. Curr Opin Obstet Gynecol 2005, I 7:135-142.

2. McCormick MC: The contribution of low birth weight to infant mortality and childhood morbidity. N Engl J Med 1985, 3 I 2:82-90.

3. Wilcox AJ, Russell IT: Birthweight and perinatal mortality: II. On weight-specific mortality. Int J Epidemiol I983, | 2:31 9-325.

4. Forssas E, Gissler M, Sihvonen M, Hemminki E: Maternal predictors of perinatal mortality: the role of birthweight. Int J Epidemiol 1999, 28:475-478.

5. Barker DJ: The developmental origins of adult disease. J Am Coll Nutr 2004, 23:588S-595S.

6. Osmond C, Barker DJ: Fetal, infant, and childhood growth are predictors of coronary heart disease, diabetes, and hypertension in adult men and women. Environ Health Perspect 2000, I 08 Suppl 3:545-553.

7. Godfrey KM, Barker DJ: Fetal nutrition and adult disease. Am J Clin Nutr 2000, 7I: I344S-1352S.
8. Richards M, Hardy R, Kuh D, Wadsworth ME: Birth weight and cognitive function in the British 1946 birth cohort: longitudinal population based study. BMJ 200I, 322:199-203.

9. Zhang X, Cnattingius S, Platt RW, Joseph KS, Kramer MS: Are babies born to short, primiparous, or thin mothers "normally" or "abnormally" small? J Pediatr 2007, 150:603-7, 607.

10. Bakketeig LS, Hoffman HJ: The tendency to repeat gestational age and birth weight in successive births, related to perinatal survival. Acta Obstet Gynecol Scand 1983, 62:385-392.

II. Skjaerven R, Wilcox AJ, Russell D: Birthweight and perinatal mortality of second births conditional on weight of the first. Int J Epidemiol 1988, 17:830-838.

12. Skjaerven R, Gjessing HK, Bakketeig LS: New standards for birth weight by gestational age using family data. Am J Obstet Gynecol 2000, I 83:689-696.

13. Beaty TH, Skjaerven R, Breazeale DR, Liang KY: Analyzing sibship correlations in birth weight using large sibships from Norway. Genet Epidemiol 1997, 14:423-433.

14. Melve KK, Skjaerven R: Birthweight and perinatal mortality: paradoxes, social class, and sibling dependencies. Int J Epidemiol 2003, 32:625-632.

15. Bakketeig LS, Jacobsen G, Skjaerven R, Carneiro IG, Knudsen LB: Low birthweight and mortality: the tendency to repeat low birthweight and its association with early neonatal and infant morbidity and mortality. Paediatr Perinat Epidemiol 2006, 20:507-5II.

16. Basso O, Frydenberg M, Olsen SF, Olsen J: Two definitions of "small size at birth" as predictors of motor development at six months. Epidemiology 2005, 16:657-663.

17. Pedersen CB, Gotzsche H, Moller JO, Mortensen PB: The Danish Civil Registration System. A cohort of eight million persons. Dan Med Bull 2006, 53:44I-449.

18. Knudsen LB, Olsen J: The Danish Medical Birth Registry. Dan Med Bull 1998, 45:320-323.

19. David RJ: Population-based intrauterine growth curves from computerized birth certificates. South Med J 1983, 76: $|40|-\mid 406$.

20. Tentoni S, Astolfi P, De Pasquale A, Zonta LA: Birthweight by gestational age in preterm babies according to a Gaussian mixture model. BJOG 2004, I I I:3 I-37.

21. Skjaerven R, Bakketeig LS: Classification of small-for-gestational age births: weight-by-gestation standards of second birth conditional on the size of the first. Paediatr Perinat Epidemiol 1989, 3:432-447.

22. Gjessing HK, Skjaerven R, Wilcox AJ: Errors in gestational age: evidence of bleeding early in pregnancy. Am J Public Health 1999, 89:213-218.

23. Platt RW, Abrahamowicz M, Kramer MS, Joseph KS, Mery L, Blondel $B$, Breart G, Wen SW: Detecting and eliminating erroneous gestational ages: a normal mixture model. Stat Med 200I, 20:349I-3503.

24. Joseph KS, Kramer MS, Allen AC, Mery LS, Platt RW, Wen SW: Implausible birth weight for gestational age. Am J Epidemiol 2001, 153:110-113.

25. Inc. SASI: The NLMIXED Procedure. SAS/STAT 9.I User's Guide 2004:3045-3142 [http://support.sas.com/documentation/onlinedoc/ 91pdf/sasdoc 91/stat ug 73/3.pdf]. Cary, NC: SAS Institute Inc.

26. Inc. SASI: The MIXED Procedure. SAS/STAT 9.1 User's Guide 2004:2659-2852 [http://support.sas.com/documentation/onlinedoc/ 91 pdf/sasdoc 91/stat ug 73/3.pdf]. Cary, NC,, SAS Institute Inc.

27. Breslow NE, Day NE: Statistical Methods in Cancer Research Volume II The Design and Analysis of Cohort Studies IARC Scientific Publications No. 82; 1987.

28. Inc. SASI: The GENMOD Procedure. SAS/STAT 9.I User's Guide 2004:1609-1730 [http://support.sas.com/documentation/onlinedoc/ 91pdf/sasdoc 91/stat ug 7313.pdf]. Cary, NC,, SAS Institute Inc.

29. Wilcox MA, Johnson IR, Maynard PV, Smith SJ, Chilvers CE: The individualised birthweight ratio: a more logical outcome measure of pregnancy than birthweight alone. $\mathrm{Br} J$ Obstet Gynaecol 1993, 100:342-347.

30. Blair EM, Liu Y, de Klerk NH, Lawrence DM: Optimal fetal growth for the Caucasian singleton and assessment of appropriateness of fetal growth: an analysis of a total population perinatal database. BMC Pediatr 2005, 5: 13.

31. Haig D: Meditations on birth weight: is it better to reduce the variance or increase the mean? Epidemiology 2003, 14:490-492. 
32. Brooks AA, Johnson MR, Steer PJ, Pawson ME, Abdalla HI: Birth weight: nature or nurture? Early Hum Dev 1995, 42:29-35.

33. Basso $O$, Wilcox AJ, Weinberg CR: Birth weight and mortality: causality or confounding? Am J Epidemiol 2006, 164:303-31I.

\section{Pre-publication history}

The pre-publication history for this paper can be accessed here:

http://www.biomedcentral.com/1471-2393/7/28/prepub

Publish with Biomed Central and every scientist can read your work free of charge

"BioMed Central will be the most significant development for disseminating the results of biomedical research in our lifetime. " Sir Paul Nurse, Cancer Research UK

Your research papers will be:

- available free of charge to the entire biomedical community

- peer reviewed and published immediately upon acceptance

- cited in PubMed and archived on PubMed Central

- yours - you keep the copyright

Submit your manuscript here:

http://www.biomedcentral.com/info/publishing_adv.asp 